\title{
Post-fire vegetation recovery in Portugal based on spot/vegetation data
}

\author{
C. Gouveia ${ }^{1,2}$, C. C. DaCamara ${ }^{1}$, and R. M. Trigo ${ }^{1,3}$ \\ ${ }^{1}$ CGUL, IDL, Faculdade de Ciências, Universidade de Lisboa, Lisboa, Portugal \\ ${ }^{2}$ Escola Superior de Tecnologia, Instituto Politécnico de Setúbal, Setúbal, Portugal \\ ${ }^{3}$ Departamento de Engenharias, Universidade Lusófona, Lisboa, Portugal
}

Received: 1 October 2009 - Revised: 15 February 2010 - Accepted: 21 February 2010 - Published: 8 April 2010

\begin{abstract}
A procedure is presented that allows identifying large burned scars and the monitoring of vegetation recovery in the years following major fire episodes. The procedure relies on 10-day fields of Maximum Value Composites of Normalized Difference Vegetation Index (MVC-NDVI), with a $1 \mathrm{~km} \times 1 \mathrm{~km}$ spatial resolution obtained from the VEGETATION instrument. The identification of fire scars during the extremely severe 2003 fire season is performed based on cluster analysis of NDVI anomalies that persist during the vegetative cycle of the year following the fire event. Two regions containing very large burned scars were selected, located in Central and Southwestern Portugal, respectively, and time series of MVC-NDVI analysed before the fire events took place and throughout the post-fire period. It is shown that post-fire vegetation dynamics in the two selected regions may be characterised based on maps of recovery rates as estimated by fitting a monoparametric model of vegetation recovery to MVC-NDVI data over each burned scar. Results indicated that the recovery process in the region located in Central Portugal is mostly related to fire damage rather than to vegetation density before 2003, whereas the latter seems to have a more prominent role than vegetation conditions after the fire episode, e.g. in the case of the region in Southwestern Portugal. These differences are consistent with the respective predominant types of vegetation. The burned area located in Central Portugal is dominated by Pinus Pinaster whose natural regeneration crucially depends on the destruction of seeds present on the soil surface during the fire, whereas the burned scar in Southwestern Portugal was populated by Eucalyptus that may quickly re-sprout from buds after fire. Besides its simplicity, the monoparametric model of vegeta-
\end{abstract}

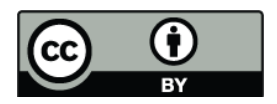

Correspondence to: C. Gouveia (cmgouveia@fc.ul.pt) tion recovery has the advantage of being easily adapted to other low-resolution satellite data, as well as to other types of vegetation indices.

\section{Introduction}

Because of the usually high levels of inflammable material associated with low moisture contents, wildfire activity represents one of the main disturbances of Mediterranean ecosystems (Trabaud, 1987), playing a key role in the dynamics and structure of plant and animal communities (Elvira and Hernando, 1989). Fire usually destroys or depletes vegetation rapidly, in contrast to fire recovery that is a long-term process. Some of the plant communities in the Mediterranean ecosystems, known as resprouter species, have high elasticity after a fire because they are often able to regenerate by means of resprouting from fire resistant structures (López-Soria and Castell, 1992; Hodgkinson, 1998). Other species, the so-called obligate seeders, rely on the germination of fire protected seeds stored in the soil or in the canopy (Lloret, 1998; Arianoutsou and Ne'eman, 2000). However, not all Mediterranean species are able to survive fire episodes (Retana et al., 2002; Lloret and Vilà, 2003).

The number of fires and the extent of the burned surface in Mediterranean Europe have increased significantly during the last decades (Röder et al., 2008). This may be either due to land-use changes (e.g. land abandonment and fuel accumulation) or to climatic changes (e.g. reduction of fuel humidity, due to prolonged drought events) that increase fire risk and fire spread (Millán et al., 1998; Pausas and Vallejo, 1999), or to a combination of both. In addition, the accumulation of fuel and the homogenization of the landscape (following land abandonment) increase the probability for

Published by Copernicus Publications on behalf of the European Geosciences Union. 
accidentally lit fires and arson (Moreno et al., 1998; Moreno, 1999). At the landscape level, post-fire regeneration depends mainly on initial vegetation and onsite environmental factors, as given by climatic and terrain parameters (Pausas and Vallejo, 1999). Vegetation cover plays, in turn, a key role on soil erosion and land degradation processes (Shakesby et al., 1993; DeBano, 2000; De Luis et al., 2001). Moreover, the destruction of vegetation by wildfires generally leads to an intensification of runoff and erosive processes (Inbar et al., 1997, 1998; De Luis et al., 2003). Thornes (1990) has suggested that a minimum of $30 \%$ vegetation cover is required to protect soils against water erosion. Studies performed at various spatial scales and under different ecological conditions indicate that the majority of loss of sediments occur during the first year after fire occurrence (DeBano et al., 1998; Inbar et al., 1998; Cerdà and Doerr, 2005) and that the risk of post-fire soil erosion increases with the time required for vegetation to reach the minimal threshold cover (Shakesby et al., 1993; Inbar et al., 1998). Therefore, a thorough evaluation of vegetation recovery after fire events becomes crucial in land management (Wittenberg et al., 2007).

Interactions between fire severity, vegetation recovery and climate are, however, still not fully understood, namely at the scale of large fires. At this scale, remote-sensing imagery has proven to be especially suitable for monitoring plant regeneration after fire (Malingreau et al., 1985; Viedma et al., 1997; Díaz-Delgado and Pons, 2001) and for spectrally recognizing fire severity (Caetano et al., 1994, 1996; White et al., 1996). A considerable number of fire recovery studies, based on remote sensing, have been conducted in regions characterised by Mediterranean climates (Jakubauskas et al., 1990; Marchetti et al., 1995; Viedma et al., 1997; Díaz-Delgado et al., 1998, 2003; Úbeda et al., 2006; Röder et al., 2008; Vila and Barbosa, 2009). Some of them focus on a specific fire event, hence, incorporating a pre-specified time span using a limited number of images (e.g. Marchetti et al., 1995; DíazDelgado and Pons, 2001; Díaz-Delgado et al., 2003). Several authors have tested the use of Normalized Difference Vegetation Index (NDVI) to monitor plant regeneration after fire (Malingreau et al., 1985; Paltridge and Barber, 1988; Viedma et al., 1997). The Enhanced Vegetation Index (EVI) that accounts for residual atmospheric contamination (e.g. by aerosols) and variable soil background reflectance has also been used for monitoring vegetation structure and function with successful results (Wittenberg et al., 2007). A different approach to post-fire regeneration monitoring, based on Spectral Mixture Analysis (SMA), has also been adopted by several authors (Viedma et al., 1997; Röder et al., 2008). Since SMA may be used to discriminate ash and charcoal, it allows for the conclusion on fire severity; however this approach appears to be more appropriate for the data recorded with hyperspectral sensors due to their higher spectral dimensionality (e.g. Riaño et al., 2002).

The aim of the present paper is to develop a general procedure that allows for the identifying of large burned scars and to monitor vegetation recovery processes during the following years. The procedure relies on monthly values of the NDVI, with a $1 \mathrm{~km} \times 1 \mathrm{~km}$ spatial resolution, as obtained from the VEGETATION instrument. The study is applied to the fire season of 2003, the worst ever recorded in Portugal since 1980 (Trigo et al., 2006). The identification of large fire scars is first performed based on cluster analysis of NDVI anomalies that persist during the vegetative cycle of the year following the fire event. Two severely burned large scars, located in Central and Southwestern Portugal, respectively, are selected and the time series of NDVI studied before the fire events and throughout the post-fire recovering period. It is then shown that post-fire vegetation dynamics may be characterised by means of a monoparametric model that allows the estimating of recovery rates. The dynamics of the regeneration processes over the two selected regions are analysed and compared by means of maps of recovery rates, obtained by fitting the proposed monoparametric statistical model to the time series of NDVI over each burned scar. The roles played by vegetation density before the fire events and by fire damage are examined and differences between the two regions explained in terms of the predominant types of vegetation.

\section{Rationale}

Post-fire dynamics is a complex phenomenon, which depends on a combination of factors from local physiography and climate to pre-fire vegetation conditions (Quinn, 1986; De Luis et al., 2001, 2004; Lloret and Vilà, 2005). In the case of the Iberian Peninsula, as in other Mediterranean regions, water availability is a major limiting factor (Le Houerou, 1988; Gouveia et al., 2008, 2009), with the vegetation cover tending to be denser in areas with higher water availability than in drier areas (Kutiel, 2000; Lloret et al., 2005). Post-fire regeneration rates in these regions are, therefore, different as a result of a decrease (increase) of resprouters (obligate seeders) that occurs when aridity increases (Pausas and Vallejo, 1999; Pausas et al., 2004; Lloret et al., 2005). These differences may be related to a better ability of seeders (when compared to resprouters) to survive in poor nutrient sites than during drought events (Knox and Clarke, 2005). Moreover, the proportion of resprouters to obligate seeders may be determined by changes in the disturbance regime and by climatic factors (Noble and Gitay, 1996; Flannigan et al., 2000).

Several studies have shown that rapid regeneration occurs within the first 2 years after the fire occurrences (Trabaud, 1981; Inbar et al., 1998), with distinct recovery rates at the north and the south facing slopes (Cerdà and Doerr, 2005). For instance, Pausas and Vallejo (1999) have shown that on the Iberian Peninsula, one year after a given fire event, vegetation cover reached $52 \%$ on the north-facing slope and only $32 \%$ on the south-facing slope. Similar trends 
were found at the Mt. Carmel region, Israel, after the 1988 fire event (Kutiel, 1994; Inbar et al., 1998). Lower levels of vegetation greenness, after the second of two successive fires occurring within an 11-year interval, have been observed by Díaz-Delgado et al. (2002), an indication that green biomass diminishes significantly when disturbances occur within short time intervals. The authors concluded that increased fire frequency might reduce ecosystem resilience, i.e. the ability of the system to recover up to a pre-disturbance state.

Fire effects on plant and soil vary according to fire intensity and time of exposure. Fire intensity is considered to be one of the most significant parameters for recognition of the fire regime of a specific region. Fire intensity affects resprouting potential, the number of viable seeds after a fire, soil nutrient status and post-burn species and characteristics (DeBano et al., 1979; Malanson and Trabaud, 1988). On the other hand, fire severity integrates physical, chemical and biological changes occurring in a given area as a consequence of fire (White et al., 1996) and is related to plant damage. Fire produces immediate effects on aerial vegetation, which becomes evident by total plant death or by partial destruction. However, high canopy trees may not be affected by ground fires due to the vertical discontinuity of fuel that avoids fire achieving the canopies. The vegetation response depends on the different plant strategies for regeneration after fire (Úbeda et al., 2006).

In 2003, Portugal was hit by the most devastating sequence of large fires, responsible for a total burned area of $450000 \mathrm{ha}$ (including 280000 ha of forest), representing about $5 \%$ of the Portuguese mainland (Trigo et al., 2006). According to Nunes et al. (2005), who have analysed a set of 506 fires that burned in Portugal in 1991, another extremely severe fire season, very large fires (larger than 1500 ha) mainly occur in maritime pine (Pinus pinaster) stands, followed by Eucalyptus (Eucalyptus globulus) plantations and Eucalyptus/pine mixed forests and then by shrublands. The authors further pointed out that maritime pine stands are mainly found in northern and central Portugal having a typical density lower than 600 trees ha $^{-1}$, whereas Eucalyptus plantations are mainly located in western Portugal with a density usually higher than pine stand but typically below 900 trees ha $^{-1}$.

Two areas, hereafter referred to as Regions I and II, were accordingly chosen; the first one located in Central Portugal and the other one in the Southwestern region of Algarve. Each chosen area was severely affected by wildfires in 2003 that led to burned scars larger than 80000 ha each. It may be noted that the spatial extent of each burned scar is larger than the annual average of total burned areas in Mediterranean countries such as France and Greece (Barbosa et al., 2007). According to the Corine Land Cover 2000 (CLC2000) classification (Fig. 1, left panel), Region I is predominantly (around $80 \%$ ) occupied by coniferous forest (identified by the dark green colour), whereas most pixels located in Region II (about 70\%) correspond to broadleaved forest (iden-
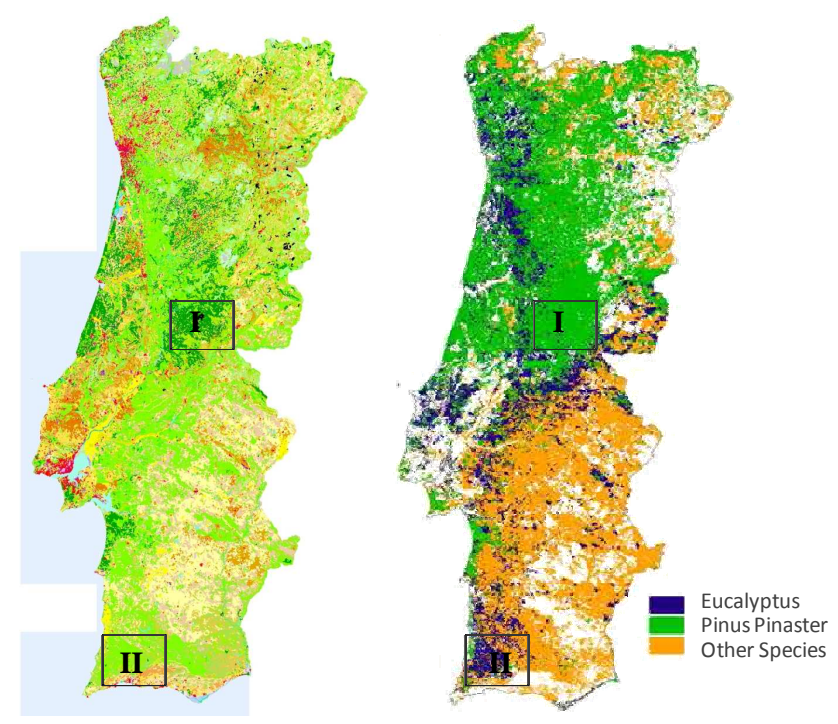

Fig. 1. Map of vegetation types over Portugal (left panel) according to the Corine Land Cover 2000 (CLC2000) classification and map of distribution of Eucalyptus and Pinus Pinaster over Portugal (right panel) provided by the Portuguese National Forest Authority (ANF). Rectangular frames in both panels indicate the geographical location of the two selected Regions, I and II, respectively in Central and in Southwestern Portugal.

tified by the light green colour). Complementary information about the dominating species in the two regions may be found in the map (Fig. 1, right panel) provided by the Portuguese National Forest Authority (ANF) and it may be observed that Region I is dominated by Pinus Pinaster, whereas Eucalyptus is the predominant species in Region II.

The differences in post-fire vegetation recovery are, therefore, to be expected in Regions I and II because of the respective types of predominant vegetation. On the one hand, since Pinus Pinaster is an obligate seeder that responds to fire through rapid seed dispersal, post-fire regeneration in Region I will crucially depend on the destruction of seeds present on the soil surface during the fire episode (Calvo et al., 2008). Accordingly, it may be anticipated that the magnitude of fire damage will play a major role in the vegetation dynamics over Region I. On the other hand, the burnt scar in Region II was mainly populated by Eucalyptus, a species that is able to vegetatively regenerate branches along their trunks from buds located beneath the bark (Burrows, 2002). Since Eucalyptus is a species characterised by a very rapid recovery process (Catry et al., 2006), recovery time over Region II is expected to depend on vegetation density rather than fire damage. 


\section{Data}

Vegetation dynamics is assessed based on fields of NDVI as derived from images acquired by the VEGETATION instrument on-board SPOTs 4 and 5 satellites. VEGETATION is an optical multi-spectral instrument that performs a daily, and almost complete, cover of the Earth with a spatial resolution of $1 \mathrm{~km}^{2}$ in four spectral bands (Hagolle et al., 2003). NDVI data were extracted from the so-called S10 products of the VITO database (http://free.vgt.vito.be) which are provided on a 10-day basis as derived using the Maximum Value Composite method (MVC). The method simply consists of selecting, for each pixel, the maximum NDVI among 10 consecutive daily images (Holben, 1986). MVC-NDVI values are supplied on a regular latitude-longitude grid at the resolution of $0.008928^{\circ}$ (corresponding to cells over Portugal of about 750 by $1000 \mathrm{~m}$ in the zonal and meridional directions, respectively). The considered period ranges from 1988 to 2006 and the selected region extends from $37^{\circ} \mathrm{N}$ to $42^{\circ} \mathrm{N}$ and from $9^{\circ} \mathrm{W}$ to $6^{\circ} \mathrm{E}$.

Data from the MVC-NDVI set were geometrically calibrated as well as atmospherically and radiometrically corrected. Geometric corrections aimed at mitigating system effects like satellite location and orientation. The atmospheric correction, which includes both absorption and scattering processes, is based on a modified version of the Simple Method for the Atmospheric Correction (SMAC) code (Rahman and Dedieu, 1994; Vermote et al., 1997). Radiometric corrections of instrument calibration effects rely on a linear model that normalizes the Charge-Coupled Device (CCD) response. Further details on the correction methods may be found in Maisongrande et al. (2004).

Time series of MVC-NDVI composites have proven to be a source of important information for monitoring surface vegetation greenness at the global and regional scales (Zhou et al., 2001; Lucht et al., 2002; Nemani et al., 2003). Nevertheless, some problems have been identified related to cloud contamination, shadows and snow, sun/view directional dependence of the spectral response as well as with the dependence of phenological changes both on time of observation and on geographical location. In order to create a consistent dataset of vegetation dynamics, each annual time-series of MVC-NDVI was analysed and corrected, according to the procedure applied by Stockli and Vidale (2004) to the Pathfinder NDVI data in order to create a continuous European vegetation phenology dataset at a 10-day temporal and a $0.1^{\circ}$ spatial resolution. The methodology relies on the application of an adjustment algorithm based on a weighted second-order Fourier analysis of the data, as previously described by Sellers et al. (1997) and Los (1998). Further details may be found in Gouveia et al. (2009).

\section{Methodology}

The methods used in the present work fall into two main categories:

- unsupervised clustering of the spatial distribution of monthly values of MVC-NDVI over Portugal as well as of the distributions of post fire recovery time of vegetation vs. vegetation density and of recovery time vs. fire damage over the burned scars inside selected Regions I and II;

- fitting of a monoparametric model of post-fire vegetation recovery to monthly deviations of NDVI spatially averaged over the burned scars inside selected Regions I and II.

\subsection{Data clustering}

Unsupervised clustering is performed based on the so-called K means (MacQueen, 1967; Hartigan and Wong, 1975) that is one of the simplest methods of partition clustering. The algorithm uses an iterative refinement technique that aims at minimizing the sum of squares of distances between data and the corresponding cluster centroid. For this purpose, data points are displaced from cluster to cluster until the sum cannot be decreased any further. The result is a set of clusters that are optimally compact and separated.

\subsection{Model of vegetation recovery}

Designed to capture the contrast between red and nearinfrared reflection of solar radiation by vegetation, NDVI has been widely used in studies of vegetation phenology and interannual variability of vegetation greenness (Gouveia et al., 2008) and has proved to be particularly useful for monitoring plant regeneration after fire events. Let $\mathrm{NDVI}(t)$ indicate vegetation greenness at time $t$ at a given location and let the lack of greenness, $y(t)$, be defined as:

$y(t)=\operatorname{NDVI}(t)-\operatorname{NDVI}^{*}(t)$

where $\operatorname{NDVI}^{*}(t)$ is an asymptotic annual cycle representing an ideally healthy state of vegetation along the phenological year. According to the definition, $\operatorname{NDVI}^{*}(t)$ is a periodic function, with a period of one year.

Let the instantaneous recovery rate, $d y / d t$, be proportional to the lack of greenness, i.e.

$\frac{d y}{d t}=-b y$

where $b$ is a positive constant and the minus sign ensures that the recovery rate is a positive quantity (given the fact that $y(t)$ is always negative). 
Integration of the previous ordinary differential equation leads to

$y(t)=a e^{-b t}$

where $a=\operatorname{NDVI}(t=0)-\mathrm{NDVI}^{*}(t=0)$ is a negative constant representing the lack of greenness at the time of occurrence of the fire event. It is worth noting that parameter $a$ corresponds to the largest negative value of $y(t)$ (i.e. largest lack of greenness) and may, therefore, be viewed as an indicator of fire damage, whereas parameter $b$ characterises the vegetation recovery rate. Similar models have been proposed in different domains of environmental science, e.g. for the build-up and decomposition of organic matter (Olson, 1963) and for the so-called biological oxygen demand (BOD) of polluted water (Sawyer et al., 2002). In this particular case, the concept of BOD is very similar to the above proposed concept of lack of greenness, since it represents the amount of oxygen required by aerobic micro-organisms to decompose the organic matter in the sample of water.

The proposed model (Eq. 3) involves prescribing three parameters, namely $\mathrm{NDVI}^{*}, a$ and $b$. In the present study, monthly means of NDVI* were estimated based on the annual cycle of maximum NDVI for each month over the considered period. This particular estimate will be hereafter referred to as the Gorgeous Year (GY) of vegetation at a given location. For instance, the annual cycles of GY for Regions I and II are represented by the black curves in Fig. 4. The value of $a$ was simply prescribed based on the observed monthly value of NDVI of the month immediately following the fire event. Finally, using the time series of observed monthly values of $\ln [y(t) / a]$ following the fire event i.e. of the natural logarithm of

$$
\frac{y(t)}{a}=\frac{\mathrm{NDVI}(t)-\mathrm{GY}(t)}{\operatorname{NDVI}(t=0)-\mathrm{GY}(t=0)}
$$

the value of $b$ was estimated by means of regression analysis performed on the following linear model in $b$ equivalent to the one given by Eq. (3)

$\ln \left[\frac{y(t)}{a}\right]=-b t$

The described procedure is comparable to the one proposed by Díaz-Delgado and Pons (2001) who selected several burned areas and then monitored the regeneration process of different plant communities. Recovery rates were estimated by means of logarithmic regression models (Díaz-Delgado et al., 1998, 2003) and the authors have used spatial averages of NDVI, as obtained from Multispectral Scanner (MSS) on board Landsat 1-5 satellites, over each selected burned area. Spatial averages over nearby control areas (not burned), which shared comparable phenological behaviour and similar dominant species composition, were also used to remove the seasonal cycle of NDVI. It is worth noting that, in our approach, the GY years play a similar role than the control

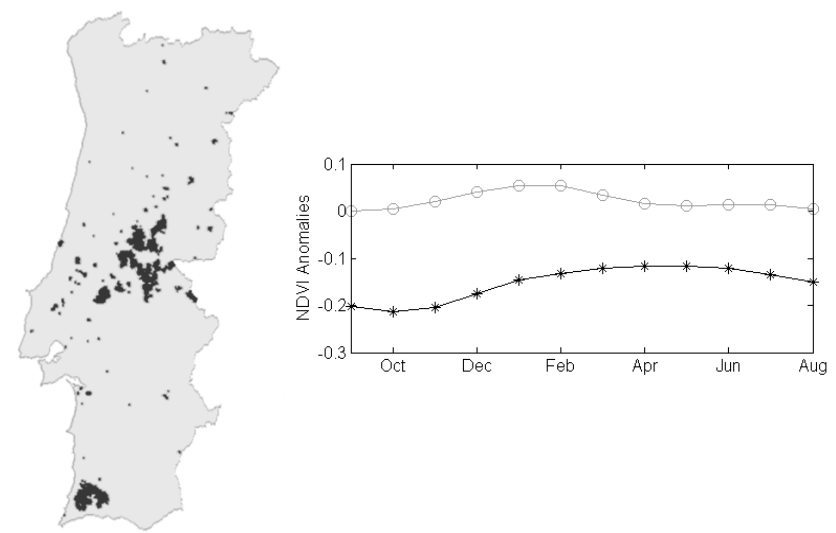

Fig. 2. Burned areas in Continental Portugal during the fire season of 2003 (black pixels in the left panel) as identified by means of cluster analysis and annual cycles of monthly MVC-NDVI anomalies that characterise the centroids of the two identified clusters (right panel), respectively associated to burned pixels (black solid circles) and non-burned pixels (grey open circles).

areas. In fact, the use of control areas was impaired in our study because of the heterogeneity of the vegetation background in Region I and due to the fact that virtually all the forest was burned during the fire episode Region II.

\section{Results}

Because of the wet characteristics of the hydrological year of 2003-2004, defined as the period from September 2003 to August 2004 (Gouveia et al., 2009), large burned scars in Portugal during the 2003 fire season appear associated with extremely low values of MVC-NDVI that persisted during the vegetative cycle of the year following the fire event. This feature allowed large burned scars to be identified by means of K-means clustering performed on 12monthly MVC-NDVI anomalies from September 2003 to August 2004, defined as departures of values of a given month from the median of that month (computed over the considered period of 1998-2006). It is worth noting that, taking into account the small length of the sample (8 years), the procedure adopted by Gouveia et al. (2009) was followed and the median was used (instead of the mean) in order to avoid the lever effect of the extremely low NDVI values that were attained in the drought years.

As shown in Fig. 2 (right panel), cluster analysis allows for the identifying of two clusters whose centroids are associated with monthly NDVI anomalies of opposite behaviour throughout the year; one of the centroids (black solid circles) is characterised by systematic negative values of monthly anomalies, whereas the other one (grey open circles) is associated to non-negative values, in particular from November to April. The spatial distribution of the two identified clusters (Fig. 2, left panel) was visually checked against the official 


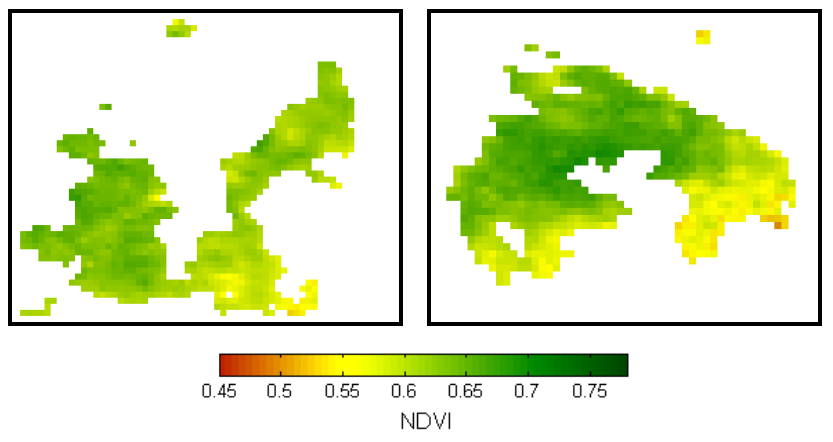

Fig. 3. Spatial distributions of the median of NDVI in May 19992003 over Region I (left panel) and Region II (right panel).

chart of wildfires provided by ANF (not shown), which is based on information from end-of-fire season Landsat imagery. As expected, pixels belonging to the first cluster (black pixels in left panel) clearly matched burned areas in the ANF chart, providing a strong indication that the developed procedure, based on the analysis of strongly negative anomalies of NDVI that persist during the vegetative cycle of the year following the fire event, leads to an adequate identification of large burned scars.

The distribution of the median fields of MVC-NDVI in May over Regions I and II is presented in Fig. 3. It may be noted that the computation of the median was restricted to the period 1999-2003 in order to exclude the signature of the fire events. With the exception of a small area located in the right bottom tip, the spatial distribution of median NDVI over Region I (Fig. 3, left panel) has a rather homogeneous character, with values of about 0.7. A stronger contrast may be observed in Region II (Fig. 3, right panel), between a greener central sector, with values of about 0.75 , and the two lower extremities, where the median NDVI is about 0.5 .

Figure 4 presents the time series of MVC-NDVI spatially averaged over Regions I and II (curves in grey). The distinct interannual cycles are worth noting, the higher (lower) interannual variability in Region II (Region I) being characteristic of broadleaved (coniferous) forest. The sharp decay in NDVI immediately after the fire events of 2003 is also well apparent and, in this respect, the overall behaviour of the annual cycles of NDVI provides a strong indication on the adequacy of using time series of NDVI to assess vegetation recovery after a large fire event. It is also worth mentioning that, besides the recurrent large summer wildfires (Pereira et al., 2005), Western Iberia was affected by severe drought episodes (VicenteSerrano, 2006). For instance, Southern Iberia was affected by an intense drought in 1999 that was responsible for the occurrence of extreme low values of NDVI, particularly during the growing season. Although the impact of the drought period was higher over arable land (Gouveia et al., 2009), the event was severe enough to also affect the broadleaved forests.
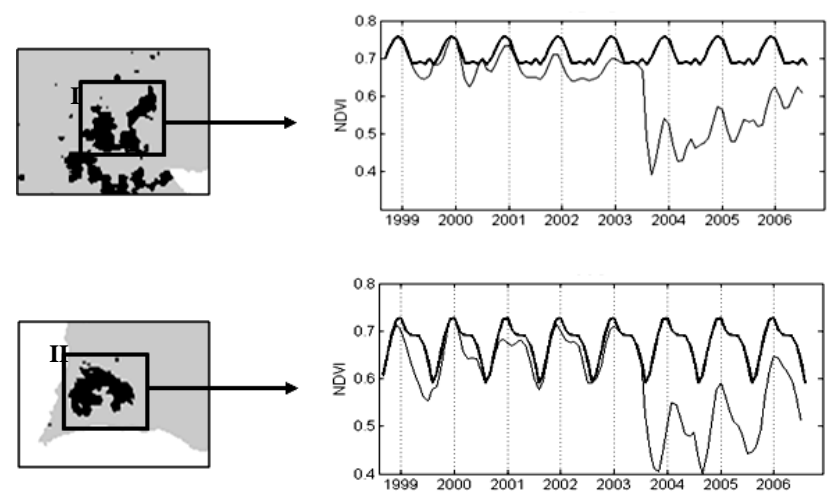

Fig. 4. Time series of NDVI (grey curves) spatially averaged over the two selected large fire scars, located in Region I (upper panel) and in Region II (lower panel), respectively. Black curves represent the Gorgeous Years (GY) of vegetation, given by the annual cycles of maximum NDVI for each month over the considered period.

Following the procedure described in Sect. 4.2, the monoparametric model of vegetation recovery, given by Eq. (5), was fit (by means of linear regression) to monthly mean values of $\ln [y(t) / a]$, given by Eq. (4), which were spatially averaged over the burned scars inside Regions I and II. The following two models were obtained:

$y=-0.3088 e^{-0.0316 t}$

$y=-0.2910 e^{-0.0389 t}$

respectively for the scars located in Regions I and II. Values of R-squared and of the corresponding 95\% confidence intervals for estimated parameter $b$ are given in Table 1 and it may be noted that more than three quarters of the variance are explained by the linear model in the case of Region I, contrasting with the case of Region II where explained variance by the model reduces to $49 \%$. The difference in goodness-of-fit in the two Regions may be understood by inspecting the time series of observed and modelled values of lack of greenness, $y$, for the two selected scars (Fig. 5). In fact, the behaviour of $y$ in the first two years following the fire events is much more irregular in the case of Region II than in the case of Region I. This is further confirmed by looking at mean annual values of lack of greenness (indicated in Fig. 5 by the large grey circles) where the fitted model is much closely followed in Region I than in Region II. Such discrepancies become attenuated during the third year in both Regions raising the possibility that the different features observed in the first two years may be due either to the severe drought of 2004-2005 that was particularly severe in Southern Portugal (Gouveia et al., 2009) or to a sensitivity of vegetation recovery in each Region to different factors (e.g. vegetation density and fire damage). This last aspect will be examined in more detail in the last section. 
Table 1. Values of R-squared $\left(R^{2}\right)$, estimates $(b)$ and $95 \%$ confidence intervals $\left(I_{95}[b]\right)$ of parameter $b$, and estimates $\left(t_{\mathrm{R}}\right)$ and $95 \%$ confidence intervals $\left(I_{95}\left[t_{\mathrm{R}}\right]\right)$ of recovery time respecting to the fit by linear regression of the monoparametric model of vegetation recovery, given by Eq. (5), in Regions I and II.

\begin{tabular}{llllll}
\hline & $R^{2}$ & $b$ & $I_{95}[b]$ & $\begin{array}{l}t_{\mathrm{R}} \\
\text { (months) }\end{array}$ & $\begin{array}{l}I_{95}\left[t_{\mathrm{R}}\right] \\
\text { (months) }\end{array}$ \\
\hline Region I & 0.77 & 0.0316 & {$[0.0286,0.0345]$} & 52 & {$[48,58]$} \\
Region II & 0.49 & 0.0389 & {$[0.0337,0.0441]$} & 43 & {$[38,49]$} \\
\hline
\end{tabular}

Figure 5 also presents estimates of recovery time, $t_{\mathrm{R}}$ (indicated by the arrows in both panels which were simply obtained by computing the instant when the modelled curve of $y$ crosses the so-called level of vegetation recovery, here defined as $90 \%$ of the mean value of $y$ during the prefire period. Accordingly, Region II has a shorter recovery time ( $t_{\mathrm{R}}=43$ months) than the one obtained in Region I $\left(t_{\mathrm{R}}=52\right.$ months). Table 1 further provides $95 \%$ confidence intervals of recovery time in both Regions and it is worth noting that even taking into account such uncertainties, there is a one-year lag of Region I in vegetation recovery which, when compared with Region II, occurs in the following vegetative cycle.

A better insight into the post fire dynamics in the two considered Regions may be obtained by studying the respective spatial variability of the recovery processes. The developed methodology was, therefore, applied to individual pixels of the two areas, i.e. to a total amount of 682 (484) pixels in Region I (II). The obtained overall distributions of recovery time, $t_{\mathrm{R}}$ (Fig. 6) are the ones to be expected, Region II (right panel) exhibiting shorter recovery times than Region I (left panel). Nevertheless, the spatial consistency is worth being stressed since it gives an indication of the robustness of the developed method. In fact, recovery times tend to form homogeneous patches that may be viewed as reflecting differences in physiographical and climatic conditions as well as in vegetation cover. Spatial discontinuities in the values of recovery time may also be identified along some bordering pixels that tend to have longer recovery times. This is, however, attributed to the coarse resolution of the data that leads to contamination of border pixels by the unburned surroundings.

Table 2 presents the relative frequencies of the obtained estimates of recovery time, $t_{\mathrm{R}}$, for the two considered regions. The contrasting characteristics of the two regions become apparent with recovery times in Region I tending to concentrate around 50 months (almost half of the pixels have recovery times in the order of 45-55 months) and Region II tending towards shorter values of recovery time (more than half of the pixels have recovery times lower than 35 months).
Table 2. Relative frequencies (\%) of different classes of recovery time, $t_{\mathrm{R}}$, (in months) with respect to Regions I and II.

\begin{tabular}{lllllrr}
\hline$t_{\mathrm{R}}$ & 25 & 35 & 45 & 55 & 65 & $\geq 75$ \\
\hline Region I & 5 & 10 & 23 & 24 & 18 & 20 \\
Region II & 8 & 47 & 26 & 10 & 5 & 4 \\
\hline
\end{tabular}
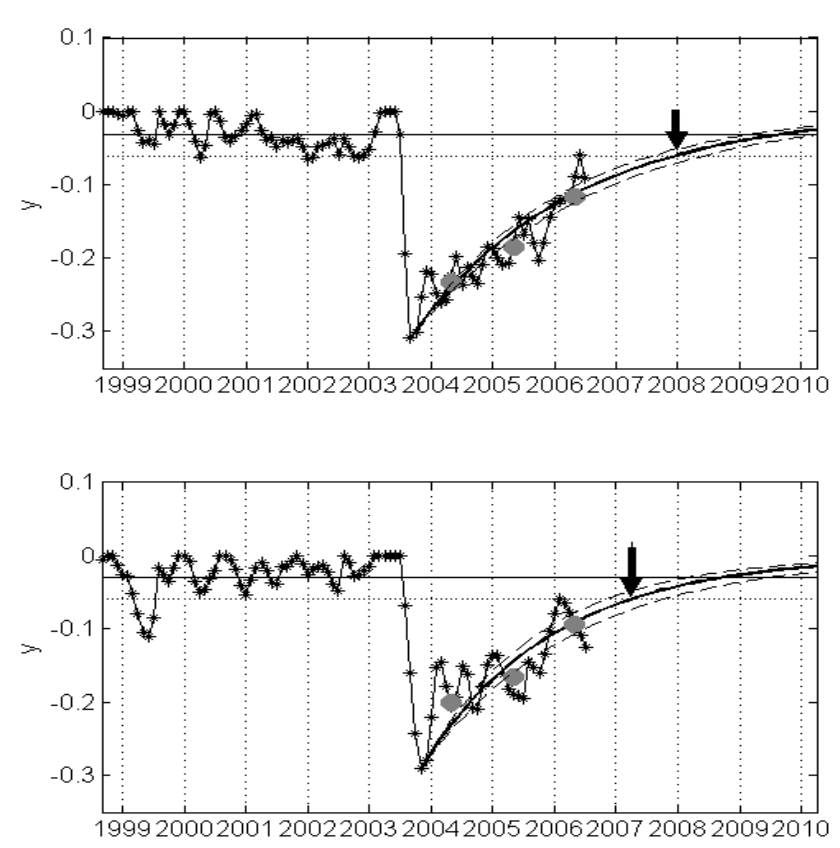

Fig. 5. Time series of observed (lines with asterisks) and modelled (bold curves) values of monthly values of lack of greenness, $y$, over the large fire scars located in Region I (upper panel) and in Region II (lower panel). The dashed curves indicate the $95 \%$ confidence limits of the regressed curve and the large grey circles indicate the annual means of $y$. The horizontal dotted line represents the level of vegetation recovery defined as $90 \%$ of the mean value of $y$ during the pre-fire period (represented, in turn, by the horizontal solid line). Arrows indicate the estimated recovery dates, defined as the instant when the modelled curves of $y$ cross the level of vegetation recovery.

Figure 7 presents the spatial distribution of monthly mean MVC-NDVI in May 2003, 2004 and 2006, i.e. respectively in the year preceding the fire events, in the following year and almost three years after the events. In 2003, just before the occurrence of the fire episodes (left panels), both regions present high levels of greenness with NDVI values of about 0.7, whereas in May of the following year (central panels) there is, as expected, a very large decrease in greenness, with the majority of values being smaller than 0.5 and dropping to as low as 0.3 . In good agreement with the spatially averaged results presented in Fig. 4, in May 2006 (right panels), 


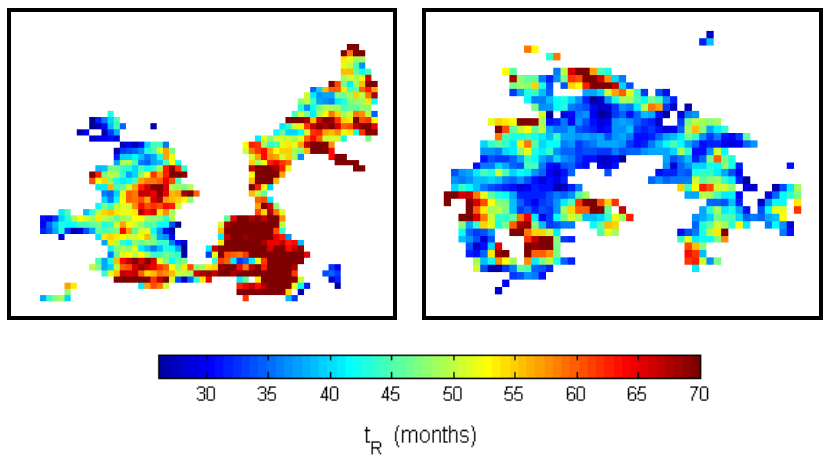

Fig. 6. As in Fig. 3, but with respect to the recovey time, $t_{\mathrm{R}}$.

i.e. 33 months after the fire event, the vegetation has considerably recovered in both regions. Several additional features, within the two regions, are worth being pointed out. For instance, in May 2004, an area of higher photosynthetic activity may be identified in the western half of Region II, which contrasts with the extremely low values in some peripheral areas in the south. On the contrary, the spatial distribution of greenness over Region I has a more homogeneous character, the exception consisting of the pixels with extremely low values of NDVI located in the southeast of the region, whose anomalously low values are still detectable in May 2006. Some pixels located along the scar boundary are suspicious because of the higher values of NDVI, but again this may be attributed to the contamination by the unburned neighbourhood.

Figures 8 and 9 present results with respect to Regions I and II when K-means clustering was performed respectively on pairs $\left\{t_{\mathrm{R}}, \mathrm{NDVI}_{\text {MEDIAN }}\right\}$ and $\left\{t_{\mathrm{R}}, \mathrm{NDVI}_{2004}\right\}$,

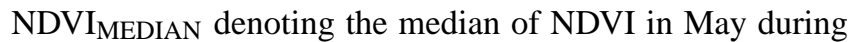
the pre-fire period (Fig. 3) and $\mathrm{NDVI}_{2004}$ referring to the field of NDVI in May 2004 (Fig. 7, central panels). Identified centroids (Figs. 8 and 9, upper panels) may indicate the existence of relationships between the analysed pairs of variables but their physical meaning has to be carefully checked, for example, by analysing the spatial distribution of obtained clusters (lower panels). The analysis allows identifying three clusters on pairs of $\left\{t_{\mathrm{R}}, \mathrm{NDVI}_{\text {MEDIAN }}\right\}$ (Figs. 8 and 9, left panels) and $\left\{t_{\mathrm{R}}, \mathrm{NDVI}_{2004}\right\}$ (right panels) which are characterised by means of dispersion diagrams (upper panels) as well as by the respective spatial distributions (lower panels) over Regions I and II.

In the case of the fire scar located in Region I, the three centroids, as obtained from the pairs of $\left\{t_{\mathrm{R}}, \mathrm{NDVI}_{2004}\right\}$ (Fig. 8, upper right panel), suggest the existence of a monotonic relationship between the two variables, the recovery time, $t_{\mathrm{R}}$, tending to increase with decreasing $\mathrm{NDVI}_{2004}$. Besides suggesting a plausible (and expectable) relationship, the three identified clusters exhibit distinct variability ranges in both variables as suggested by the absence of superposition of the interquartile ranges. The spatial distribution
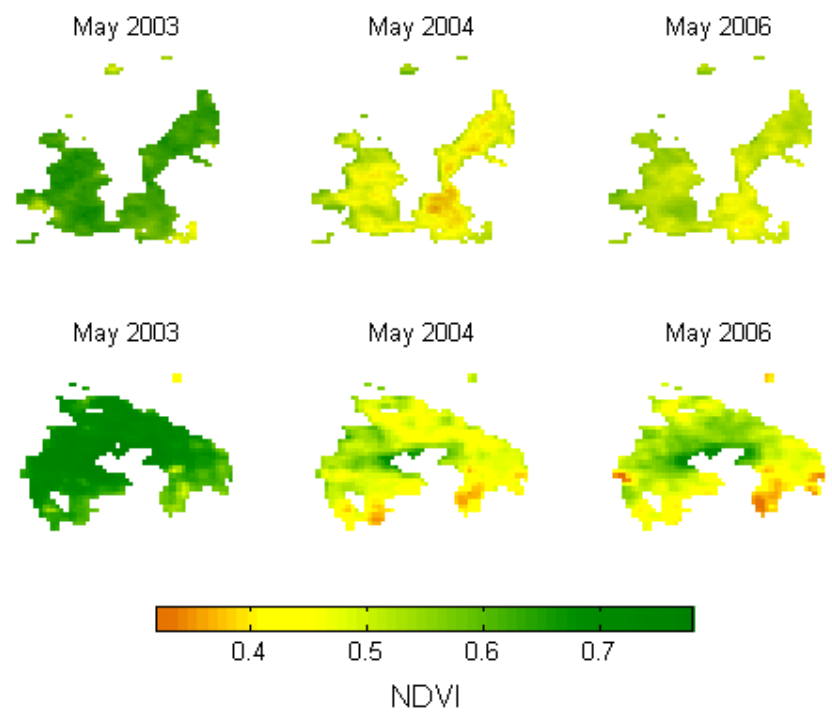

Fig. 7. Fields of NDVI in May 2003-2006 over the two selected large fire scars located in Region I (upper panels) and in Region II (lower panels).

(Fig. 8, lower right panel) of the identified clusters is also very similar to the ones of both $t_{\mathrm{R}}$ (Fig. 6, left panel) and $\mathrm{NDVI}_{2004}$ (Fig. 7, upper middle panel). The same does not happen, however, in the case of the three clusters as obtained from the pairs of $\left\{t_{\mathrm{R}}, \mathrm{NDVI}_{\text {MEDIAN }}\right\}$ (Fig. 8, left panels); differences among the clusters are due to differences in NDVI MEDIAN (and less to $t_{\mathrm{R}}$ ) and neither the obtained clusters suggest the existence of a monotonic relationship between the two parameters, nor the spatial distribution of the clusters is similar to the ones of either $t_{\mathrm{R}}$ (Fig. 6, left panel) or NDVI MEDIAN (Fig. 3, left panel).

Different results are obtained in the case of Region II. In fact, the analysis performed on pairs of $\left\{t_{\mathrm{R}}, \mathrm{NDVI}_{\text {MEDIAN }}\right\}$ leads to the identification of a very homogeneous cluster that congregates $62 \%$ of the pixels (black cluster in Fig. 9, upper left panel). This cluster corresponds to pixels characterised by dense vegetation before the fire episode and by very short recovery times, around 40 months. Moreover, the spatial distribution of this cluster (black pixels in Fig. 9, lower left panel), located over the central area of the burned scar, closely matches the distribution of either the higher values of NDVI MEDIAN (Fig. 3, right panel) and the lower values of $t_{\mathrm{R}}$ (Fig. 6, right panel). On the other hand, results obtained from the pairs of $\left\{t_{\mathrm{R}}, \mathrm{NDVI}_{2004}\right\}$ are less consistent (Fig. 9, right panels), the two more populated clusters presenting similar recovery times for different ranges of $\mathrm{NDVI}_{2004}$ and the respective spatial distributions having virtually no affinity with the spatial distributions of either $t_{\mathrm{R}}$ (Fig. 6, right panel) or $\mathrm{NDVI}_{2004}$ (Fig. 7, lower middle panel). 

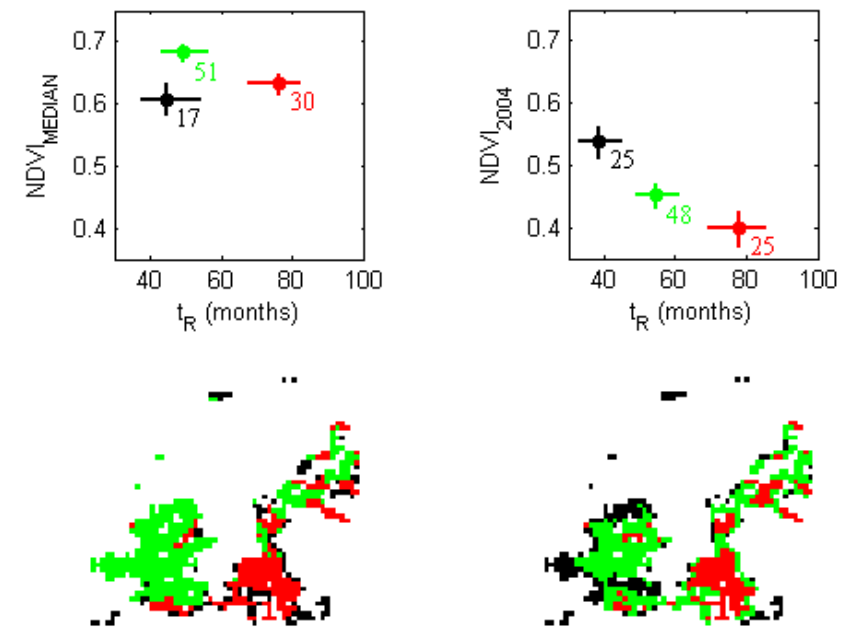

Fig. 8. Dispersion diagrams (upper panels) and spatial distribution (lower panels) of centroids as obtained from K-means clustering performed on pairs $\left\{t_{\mathrm{R}}, \mathrm{NDVI}_{\text {MEDIAN }}\right\}$ (left panels) and $\left\{t_{\mathrm{R}}, \mathrm{NDVI}_{2004}\right\}$ with respect to pixels over the large fire scar located in Region I. Clusters are coloured black, red and green by decreasing values of the NDVI MEDIAN (left panel) and $\mathrm{NDVI}_{2004}$ (right panel) of the respective centroids. Coordinates of the centroids are identified by filled circles in the dispersion diagrams, whereas horizontal and vertical bars indicate the interquartile ranges. Integer numbers next to each centroid indicate the fraction of areal coverage $(\%)$ by each cluster.

\section{Discussion and concluding remarks}

A procedure was presented aiming to identify large burned scars and monitor post-fire vegetation recovery based on 10day fields of Maximum Value Composites of Normalized Difference Vegetation Index (MVC-NDVI) as obtained from the VEGETATION instrument. By means of cluster analysis of persistent MVC-NDVI anomalies, large fire scars resulting from fire events during the extreme fire season of 2003 were identified and two regions, containing very large burned scars, Regions I and II, were then selected, respectively located in Central and Southwestern Portugal.

Post-fire vegetation dynamics in the two selected regions were then characterised based on maps of recovery rates as estimated by fitting a monoparametric model of vegetation recovery to MVC-NDVI data over each burned scar. Postfire recovery rates over extensive burned areas are likely to strongly depend on the predominant type of vegetation and this was confirmed by the obtained results in Regions I and II. In fact, the longer recovery times, $t_{\mathrm{R}}$, in the burned scar inside Region I (the southeastern corner reaching values of $t_{\mathrm{R}}$ of the order of 75 months) are consistent with the fact that the region is dominated by coniferous forests, namely $P i$ nus Pinaster, whereas the considerably shorter values of $t_{\mathrm{R}}$ observed in Region II are, in turn, consistent with the predominance of Eucalyptus (Fig. 1) and its quicker recovery process.
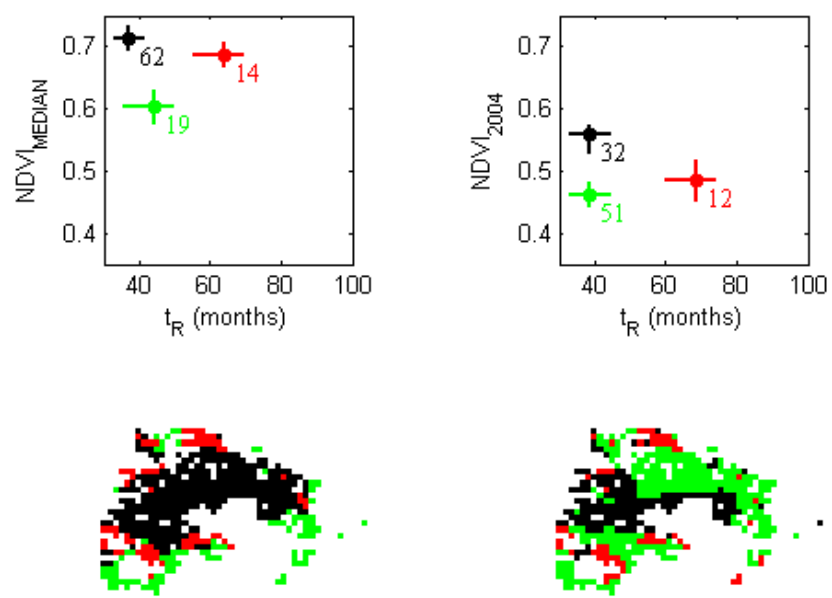

Fig. 9. As in Fig. 8, but with respect to the large fire scar located in Region II.

Three years after the fire events, the spatial distribution of monthly means of MVC-NDVI in Regions I and II presents differences with regard to homogeneity (Fig. 7), Region I presenting a rather homogeneous character that contrasts with Region II where an area of higher photosynthetic activity in the west may be identified, as opposed to the extremely low values in peripheral areas in the south. This feature, together with differences observed in the time evolution of lack of greenness in the two regions, raises the possibility of the existence of a sensitivity of vegetation recovery in each Region to different factors. In fact, besides depending on changes in density of vegetation, the spatial variability within each considered region may be related to a number of factors, which include terrain slopes (Kutiel, 1994; Inbar et al., 1998; Pausas et al., 1999; Cerdà and Doerr, 2005), climatic trends and meteorological regimes (DeLuis et al., 2001, 2004), fire frequency (Röder et al., 2008), and fire intensity and severity (Malanson and Trabaud, 1988; Zammit and Zedeler, 1988, White et al., 1996). The available dataset of MVC-NDVI allows for the assessing and comparing of the impact on vegetation recovery of two indicators of preand post-fire vegetation conditions, namely vegetation density and fire damage. In fact, the median of NDVI in May, during the pre-fire period (NDVI MEDIAN), may be viewed as an indicator of vegetation density of a given pixel, whereas the field of NDVI in May 2004 (NDVI 2004 ) may be considered as a measure of fire damage, in particular, its impact on the new phenological cycle. This latter aspect has, in fact, motivated the choice of $\mathrm{NDVI}_{2004}$ instead of either lack of greenness immediately after the fire event (i.e. parameter $a$ of Eq. 3) or NDVI in October 2003. Furthermore, $\mathrm{NDVI}_{2004}$ presents the advantage of being free from the influence of ashes and charcoal that could be misleading with low vegetation activity during the months immediately following the fire season. 
The impact on vegetation recovery, of either vegetation density or fire damage, was assessed accordingly by means of a cluster analysis performed on pairs $\left\{t_{\mathrm{R}}, \mathrm{NDVI}_{\text {MEDIAN }}\right\}$ and $\left\{t_{\mathrm{R}}, \mathrm{NDVI}_{2004}\right\}$, respectively. In the case of Region I (Fig. 8), post-fire vegetation dynamics seems to be mostly related to vegetation conditions after the fire episode (i.e. $\mathrm{NDVI}_{2004}$ ) rather than to the vegetation density before

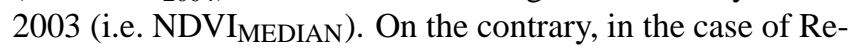
gion II (Fig. 9) the role of vegetation density, before the fire episode, seems to have been more prominent than the one played by fire damage.

The consistency of results obtained on the spatial distribution of recovery times over the two study regions, as well as of the relationships with vegetation density and fire damage, provides a strong indication that, despite its apparent simplicity, the developed model of vegetation recovery is able to provide adequate estimates of recovery times (at least for $\mathrm{Pi}$ nus Pinaster and Eucalyptus, two important western Iberian tree species). This is particularly useful since the proposed model only requires time series of NDVI of a relatively modest length, the stability of estimates being ensured partly by the fact that a single parameter is estimated by linear regression from the data. The model also has the advantage of not requiring the definition of control regions to remove the seasonal cycles of NDVI, which may be difficult to define either because of the heterogeneity of the background or because of the extension of the burned area.

Finally, current work by the authors shows that the method can be easily applied to large fire scars in other Mediterranean regions. It is also worth stressing that, although based on data from VEGETATION, the proposed model has the potential of being adapted for other low-resolution satellite data, in particular those from AVHRR as well as to other types of vegetation indices.

Acknowledgements. This work was partly supported by the EU 7th Framework Program (FUME) contract number 243888. The work was also partly supported by the Portuguese Science Foundation (FCT) through project FLAIR (PTDC/AAC-AMB/104702/2008). The NDVI dataset was kindly supplied by VITO database (http://free.vgt.vito.be).

Edited by: R. Lasaponara

Reviewed by: M. Lovallo, E. A. C. Costantini, and another anonymous referee

\section{References}

Arianoutsou, M. and Ne'eman, G.: Post-fire regeneration of natural Pinus halepensis forests in the east Mediterranean Basin, in: Ecology, biogeography and management of Pinus halepensis and P. brutia forest ecosystems in the Mediterranean Basin, edited by: Ne'eman, G. and Trabaud, L., Backhuys, Leiden, NL, 269-290, 2000.

Barbosa, P., Amatulli, G., Boca, R., Camia, A., Kucera, J., Libertà, G., San-Miguel Ayanz, J., Schmuck, G., Schulte, E., and
Dierks, H.-H.: Forest Fires in Europe 2006, EUR 22931 EN Joint Research Centre - Institute for Environment and Sustainability, Luxembourg: Office for Official Publications of the European Communities, EUR - Scientific and Technical Research series, ISSN 1018-5593, 79 pp., 2007.

Burrows, G. E.: Epicormic strand structure in Angophora, Eucalyptus and Lophostemon (Myrtaceae) - implications for fire resistance and recovery, New Phytol., 153(1), 111-131, 2002.

Caetano, M. S., Mertes, L. A. K., and Pereira, J. M. C.: Using spectral mixture analysis for fire severity mapping, in: 2nd Conference on Forest Fire Research, edited by: Oliveira, L. A., Viegas, D. X., Varela, V., and Raimundo, A. M., Coimbra: ADAI, 2, 667-677, 1994.

Caetano, M., Mertes, L., Cadete, L., and Pereira, J. M. C.: Assesment of AVHRR data for characterising burned areas and postfire vegetation recovery, EARSeL Advances in Remote Sensing, 4, 124-134, 1996.

Calvo, L., Santalla, S., Valbuena L., Marcos, E., Tárrega, R., and Luis-Calabuig, E.: Post-fire natural regeneration of a Pinus pinaster forest in NW Spain, Plant Ecol., 197, 81-90, 2008.

Catry, F. X., Rego, F. C., Bugalho, M. N., Lopes, T., Silva, J. S., and Moreira, F.: Efeitos do fogo na sobrevivência e regeneração das árvores num ecossistema mediterrânico, edited by: Viegas, D. X., V International Conference on Forest Fire Research, 2006 (in Portuguese).

Cerdà, A. and Doerr, S. H.: The influence of vegetation recovery on soil hydrology and erodibility following fire: an eleven year investigation, Int. J. Wildland Fire, 14(4), 423-437, 2005.

DeBano, L. F.: The role of fire and soil heating on water repellency in wildland environments: a review, J. Hydrol., 231/232, 195206, 2000.

DeBano, L. F., Neary, D. G., and Folliott, P. F.: Fire's Effects on Ecosystems, John Wiley and Sons, New York, 333 pp., 1998.

DeBano, L. F., Rice, R. M., and Conrad, C. E.: Soil heating in chaparral fires: effects on soil properties, plant nutrients, erosion and runoff. United States Forest Service, Research Paper PSW145, 1979.

De Luis, M., García-Cano, M. F., Cortina, J., Raventós, J., González-Hidalgo, J. C., and Sánchez, J. R.: Climatic trends, disturbances and short-term vegetation dynamics in a Mediterranean shrubland, Forest Ecol. Manag., 147, 25-37, 2001.

De Luis, M., González-Hidalgo, J. C. and Raventós, J.: Effects of fire and torrential rainfall on erosion in a Mediterranean gorse community. Land Degrad. Dev., 14, 203-213, 2003.

De Luis, M., Baeza, M. J., Raventos, J., and Gonzales-Hidalgo, J. C.: Fuel characteristics and fire behavior in mature Mediterranean gorse shrub land, Int. J. Wildland Fire, 13, 79-87, 2004.

Díaz-Delgado, R. and Pons, X.: Spatial patterns of forest fires in Catalonia (NE of Spain) along the period 1975-1995. Analysis of vegetation recovery after fire, Forest Ecol. Manag., 147, 6774, 2001.

Díaz-Delgado, R., Salvador, R., and Pons, X.: Monitoring of plant community regeneration after fire by remote sensing, in: Fire management and landscape ecology, edited by: Traboud, L., Int. Association of Wildland Fire, Fairfield, WA, 315-324, 1998.

Díaz-Delgado, R., Lloret, F., Pons, X., and Terradas, J.: Satellite evidence of decreasing resilience in Mediterranean plant communities after recurrent wildfires, Ecology, 83(8), 2293-2303, 2002. 
Díaz-Delgado, R., Lloret, F., and Pons, X. Influence of fire severity on plant regeneration through remote sensing imagery. Int. J. Remote Sens., 24(8), 1751-1763, 2003.

Elvira, L. M. and Hernando, C.: Inflamabilidad y energía de las especies de sotobosque, Instituto Nacional de Investigaciones Agrarias, Madrid, 68 pp., 1989.

Flannigan, M. D., Stocks, B. J., and Wotton, B. M.: Climate change and forest fires, Sci. Total Environ., 262, 221-229, 2000.

Gouveia, C., Trigo, R. M., DaCamara, C. C., Libonati, R., and Pereira, J. M. C.: The North Atlantic Oscillation and European Vegetation Dynamics, Int. J. Climatol., 28(14), 1835-1847, doi:10.1002/joc.1682, 2008.

Gouveia, C., Trigo, R. M., and DaCamara, C. C.: Drought and vegetation stress monitoring in Portugal using satellite data, Nat. Hazards Earth Syst. Sci., 9, 185-195, 2009,

http://www.nat-hazards-earth-syst-sci.net/9/185/2009/.

Hagolle, O., Lobo, A., Maisongrande, P., Duchemin, B., and De Pereira, A.: Quality assessment and improvement of SPOT/VEGETATION level temporally composited products of remotely sensed imagery by combination of VEGETATION 1 and 2 images, Remote Sens. Environ., 94(2), 172-186, 2005.

Hartigan, J. A. and Wong, M. A.; Algorithm AS 136: A K-Means Clustering Algorithm, J. Roy. Stat. Soc. C-App., 28(1), 100-108, 1979.

Hodgkinson, K. C.: Sprouting success of shrubs after fire: height dependent relationships for different strategies, Oecologia, 115, 64-72, 1998.

Holben, B. N.: Characteristics of maximum-value composite images from temporal AVHRR data, Int. J. Remote Sens., 7, 14171434, 1986.

Inbar, M., Wittenberg, L., and Tamir, M.: Soil erosion and forestry management after wildfire in a Mediterranean woodland, Mt. Carmel, Israel, Int. J. Wildland Fire 7, 285-294, 1997.

Inbar, M., Tamir, M., and Wittenberg, L.: Runoff and erosion processes after a forest fire in Mount Carmel, a Mediterranean area, Geomorphology, 24(1), 17-33, 1998.

Jakubauskas, M. E., Lulla, K. P., and Mausel, P. W.: Assessment of vegetation change in a fire-altered forest landscape, Photogramm. Eng. Rem. S., 56(3), 371-377, 1990.

Knox, K. J. E. and Clarke, P. J.: Nutrient availability induces contrasting allocation and starch formation in resprouting and obligate seeding shrubs, Funct. Ecol., 19, 690-698, 2005.

Kutiel, P.: Fire and ecosystem heterogeneity: a Mediterranean case study, Earth Surf. Proc. Land., 19, 187-194, 1994.

Kutiel, P.: Plant composition and plant species diversity in east Mediterranean Pinus halepensis forests, in: Ecology, biogeography and management of Pinus halepensis and P. brutia forest ecosystems in the Mediterranean Basin, edited by: Ne'eman, G. and Trabaud, L., Backhuys, Leiden, NL, 143-152, 2000.

Le Houerou, H. N.: Relationship between the variability of primary production and the variability of annual precipitation in world arid lands, J. Arid Environ., 15, 1-16, 1988

Lloret, F.: Fire, canopy cover and seedling dynamics in Mediterranean shrubland of northeastern Spain, J. Veg. Sci., 9, 417-430, 1998.

Lloret, F. and Vilà, M.: Diversity patterns of plant functional types in relation to fire regime and previous land use in Mediterranean woodlands, J. Veg. Sci., 14, 387-398, 2003.

Lloret, F., Estevan, H., Vayreda, J., and Terradas, J.: Fire regenera- tive syndromes of forest woody species across fire and climatic gradients, Oecologia, 146, 461-468, 2005.

Los, S. O.: Linkages between global vegetation and climate: an analysis based on NOAA-Advanced Very High Resolution Radiometer Data, Ph.D. thesis, Vrije Universiteit, Amsterdam, 179 pp., 1998.

López-Soria, L. and Castell, C.: Comparative genet survival after fire in woody Mediterranean species, Oecologia, 91, 493-499, 1992.

Lucht, W. I., Colin Prentice, W. I., Myneni, R. B., Sitch, S., Friedlingstein, P., Cramer, W., Bousquet, P., Buermann, W., and Smith, B.: Climatic Control of the High-Latitude Vegetation Greening Trend and Pinatubo Effect, Science, 296, 1687-1688, 2002.

MacQueen, J. B.: Some methods for classification and analysis of multivariate observations, Proc. 5th Berkeley Symposium on Mathematical Statistics and Probability 1, University of California Press, 281-297, 1967.

Maisongrande, P., Duchemin, B., and Dedieu, G.: VEGETATION/SPOT - An Operational Mission for the Earth Monitoring: Presentation of New Standard Products, Int. J. Remote Sens., 25, 9-14, 2004.

Malanson, G. P. and Trabaud, L.: Vigour of post-fire resprouting by Quercus coccifera L., J. Ecol., 76, 351-365, 1988.

Malingreau, J. P., Stephens, G., and Fellows, L.: Remote sensing of forest fires: Kalimantan and North Borneo in 1982-83, Ambio, 14, 314-321, 1985.

Marchetti, M., Ricotta, C., and Volpe, F.: A qualitative approach to the mapping of post-fire regrowth in Mediterranean vegetation with Landsat-TM data, Int. J. Remote Sens., 16(13), 2487-2494, 1995.

Millán, M. M., Estrela, M. J., and Badenas, C.: Synoptic analysis of processes relevant to forest fire dynamics on the Spanish Mediterranean coast, in: Large forest fires, edited by: Moreno, J. M., Leiden, Blackhuys Publishers, 1-30, 1998.

Moreno, J. M.: Forest Fires: Trends and implications in desertification prone areas of southern Europe, in: Mediterranean desertification. Research results and policy implications, edited by: Balabanis, P., Peter, D., Ghazi, A., and Tsogas, M., Proceedings of the international conference, 29 October to 1 November 1996 , Crete, Greece, 115-150, 1999.

Moreno, J. M. (Ed.), Vazquez, A., and Velez, R.: Recent history of forest fires in Spain, in: Large Forest Fires, Backhuys Publishers, Leiden, The Netherlands, 159-186, 1998.

Nemani, R. R., Charles, D., Keeling, C. D., Hashimoto, H., Jolly, W. M., Piper, S. C., Tucker, C. J., Myneni, R. B., and Running, S. W.: Climate-Driven Increases in Global Terrestrial Net Primary Production from 1982 to 1999, Science, 300, 1560-1563, 2003.

Noble, I. R. and Gitay, H. A.: A functional classification for predicting the dynamics of landscapes, J. Veg. Sci., 7, 329-336, 1996.

Nunes, M. C. S., Vasconcelos, M. J., Pereira, J. M. C., Dasgupta, N., Alldredge, R. J., and Rego, F. C.: Land cover type and fire in Portugal: Do fires burn land cover selectively?, Landscape Ecol., 20, 661-673, 2005.

Olson, J. S.: Energy Storage and the Balance of Producers and Decomposers in Ecological Systems, Ecology, 44(2), 322-331, 1963.

Paltridge, G. W. and Barber, J.: Monitoring grassland dryness and fire potential in Australia with NOAA-AVHRR data, Remote 
Sens. Environ., 25, 381-394. 1995.

Pausas, G. J. and Vallejo, V. R.: The role of fire in European Mediterranean Ecosystems. In: E. Chuvieco, Editor, Remote sensing of large wildfires in the European Mediterranean basin, Springer-Verlag, 3-16, 1999.

Pausas, J. G., Bradstock, R. A., Keith, D. A., Keeley, J. E., and the GCTE (Global Change of Terrestrial Ecosystems) Fire Network: Plant functional traits in relation to fire in crown-fire ecosystems, Ecology, 85, 1085-1100, 2004.

Pereira, M. G., Trigo, R. M., DaCamara, C. C., Pereira, J. M. C., and Leite, S. M.: Synoptic patterns associated with large summer forest fires in Portugal, Agr. Forest Meteorol., 129(1-2), 11-25, doi:10.1016/j.agrformet.2004.12.007, 2005.

Quinn, R. D.: Mammalian herbivory and resilience in Mediterraneanclimate ecosystems, in: Resilience in Mediterranean-type ecosystems, edited by: Dell, B., Hopkins, A. J. M., and Lamont, B. B., Dordrecht: Kluwer Academic Publishers, 113-128, 1986.

Rahman, H. and Dedieu, G.: SMAC: a simplified method for the atmospheric correction of satellite measurements in the solar spectrum, Int. J. Remote Sens., 15, 123-143, 1994.

Retana, J., Espelta, J. M., Habrouk, A., Ordoñez, J. L., and de SolaMorales, F.: Regeneration patterns of three Mediterranean pines and forest changes after a large wildfire in northeastern Spain, Ecoscience, 9, 89-97, 2002.

Riaño, D., Chuvieco, E., Ustin, S., Zomer, R., Dennison, P., and Roberts, D. A.: Assessment of vegetation regeneration after fire through multitemporal analysis of AVIRIS images in the Santa Monica Mountains, Remote Sens. Environ., 79, 60-71, 2002

Röder, A., Hill, J., Duguy, B., Alloza, J. A., and Vallejo, R.: Using long time series of Landsat data to monitor fire events and postfire dynamics and identify driving factors. A case study in the Ayora region (eastern Spain), Remote Sens. Environ., 112, 259273, 2008.

Sawyer, C. N., McCarty, P. L., and Parkin, G. F.: Chemistry for Environmental Engineering and Science, 5th edn., New York, McGraw-Hill, 752 pp., 2002.

Sellers, P. J., Dickinson, R. E., Randall, D. A., Betts, A. K., Hall, F. G., Berry, J. A., Collatz, G. J., Denning, A. S., Mooney, H. A., Nobre, C. A., Sato, N., Field, C. B., and Henderson-Sellers, A.: Modeling the exchanges of energy, water, and carbon between continents and the atmosphere, Science, 275, 502-509, 1997.

Shakesby, R. A., Coelho, C. O. A., Ferreira, A. D., Terry, J. P., and Walsh, R. P. D.: Wildfire impacts on soil erosion and hydrology in wet Mediterranean forest, Portugal. Int. J. Wildland Fire 3, 95-110, 1993.
Stockli, R. and Vidale, P. L.: European plant phenology and climate as seen in a 20-year AVHRR land-surface parameter dataset, Int. J. Remote Sens., 25, 3303-3330, 2004.

Thornes, J. (Ed.): The interaction of erosion and vegetation dynamics in land degradation: spatial outcomes, in: Vegetation and Erosion, Wiley, New York, 41-54, 1990.

Trabaud, L.: Dynamics after fire of sclerophyllous plant communities in the Mediterranean basin, Ecologia Mediterranea, 13, 2537, 1987.

Trigo, R. M., Pereira, J. M. C., Pereira, M. G., Mota, B., Calado, M. T., DaCamara, C. C., and Santo, F. E.: Atmospheric conditions associated with the exceptional fire season of 2003 in Portugal, Int. J. Climatol., 26(13), 1741-1757, 2006.

Úbeda, X., Outeiro, L. R., and Sala, M.: Vegetation regrowth after a differential intensity forest fire in a Mediterranean environment. Northeast Spain, Land Degrad, Dev., 17(4), 429-440, 2006.

Vermote, E. D., Tanré, J. L., Deuzé, M., Herman, M., and Morcrette, J. J.: Second simulation of the satellite signal in the solar spectrum, 6S: an overview, IEEE T. Geosci. Remote, 35, 675-686, 1997.

Vicente-Serrano, S. M.: Spatial and temporal analysis of droughts in the Iberian Peninsula (1910-2000), Hydrolog. Sci. J., 51, 8397, 2006.

Viedma, O., Meliá, J., Segarra, D., and Garcia-Haro, J.: Modeling rates of ecosystem recovery after fires using Landsat TM data, Remote Sens. Environ., 61, 383-398, 1997.

Vila, J. P. S. and Barbosa, P.: Postfire vegetation regrowth detection in the Deiva Marina region (Liguria Italy) using Landsat TM and ETM+ data, Ecol. Model., 221(1), 75-84, doi:10.1016/j.ecolmodel.2009.03.011, 2010.

White, J. D., Ryan, K. C., Key, C., and Running, S. W.: Remote sensing of forest fire severity and vegetation recovery, Int. J Wildland Fire, 6, 125-136, 1996.

Wittenberg, L., Malkinson, D., Beer, O., Halutzy, A., and Tesler, N.: Spatial and temporal patterns of vegetation recovery following sequences of forest fires in a Mediterranean landscape, Mt. Carmel Israel, Catena, Elsevier, 71(1), 76-83, 2007.

Zhou, L., Tucker, C. J., Kaufmann, R. K., Slayback, D., Shabanov, N., and Myneni, R. B.: Variations in northern vegetation activity inferred from satellite data of vegetation index during 1981 to 1999, J. Geophys. Res., 106(D17), 20069-20083, 2000. 